\title{
ФОРМИРОВАНИЕ ПРОФОРИЕНТАЦИОННОЙ МОТИВАЦИИ УЧАЩИХСЯ ЧЕРЕЗ СИСТЕМУ ПРАКТИКО-ОРИЕНТИРОВАННЫХ ЗАДАЧ ПО ХИМИИ
}

\section{FORMATION OF PROFESSIONAL MOTIVATION OF STUDENTS THROUGH A SYSTEM OF PRACTICALLY-ORIENTED CHEMISTRY TASKS}

E. Nelyubina

L. Panfilova

Summary: This is due to the fact that organic chemistry in itself is a practice-oriented science. Many organic concepts have arisen in the course of observations of real objects and phenomena. People got acquainted with organic substances, knowing the world around them and their body. Possession of such knowledge helped in the manufacture of materials used in housing construction, the synthesis of organic fibers from which fabric is made and sewing clothes, the manufacture of dishes and jewelry, and most importantly, the synthesis of drugs and some food products is carried out. The accumulated experience was gradually brought into a structured system.

The need to use practice-oriented tasks in teaching chemistry, providing a link between the phenomena of the real world and its real models, the formation of certain forms of thinking.

Results: the practical significance of the study is determined by the high level of readiness of the obtained results for implementation in pedagogical practice, since all design procedures are framed in methodological recommendations and can be used by organizers, methodologists, and teachers of the vocational education system for conducting classes in chemical elective chemistry courses, as well as used by chemistry teachers directly in the classroom.

The developed methodological system for the use of practice-oriented tasks in chemistry in the educational and extracurricular time, aimed at the formation of career-oriented motivation, has been tested and used in the organization of training for students in grades 10 of MBOU School No. 129, Samara

Keywords: chemistry teaching methodology, training, technology, practice-oriented task, motivation.

\author{
Нелюбина Елена Георгиевна \\ К.n.н., дочент, ФГБОУ ВО «Самарский государственный \\ социально-педагогический университет», г. Самара \\ nelubina.elena@pgsga.ru \\ Панфилова Людмила Владимировна \\ Д.п.н., професссор, ФГБОУ ВО «Самарский государственный \\ сочиально-педагогический университет», г. Самара
}

panfilova@pgsga.ru

Аннотация: Особое место с точки зрения включения в образовательный процесс практико-ориентированных задач занимает школьный курс химии, особенно раздел органической химии. Это связано с тем, что органическая химия сама по себе является практико-ориентированной наукой. Многие органические понятия возникли в ходе наблюдений реальных предметов и явлений. Люди знакомились с органическими веществами, познавая окружающий мир и свой организм. Владение такими знаниями помогало в изготовлении материалов, используемых в строительстве жилья, синтезу органических волокон из которых изготавливают ткань и шитью одежду, изготовлению посуды и украшений, а главное проводят синтезы лекарственных препаратов и некоторых продуктов питания. Накопленный опыт постепенно приводился в структурированную систему.

Необходимость применения практико-ориентированных задач в обучении химии, обеспечивающих связь между явлениями реального мира и его реальными моделями, формирование определенных форм мышления.

Результаты: практическая значимость исследования определяется высоким уровнем готовности полученных результатов к внедрению в педагогическую практику, поскольку все процедуры проектирования оформлены в методические рекомендации и могут быть использованы организаторами, методистами, преподавателями системы профессионального образования для проведения занятий по химическим элективным курсам химии, а так же могут использоваться учителями химии непосредственно на уроках.

Разработанная методическая система по использованию практико-ориентированных задач по химии в учебное и внеучебное время, направленная на формирование профориентационной мотивации, апробирована и используется при организации обучения учащихся 10 классов МБОУ Школа №129 г.0. Самара.

Ключевые слова: методика преподавания химии, обучение, технология, практико-ориентированная задача, мотивация.

стандарте основного общего образования [1], Федеральном государственном образовательном стандарте среднего общего образования [2], а так же в Фундаментальном ядре содержания общего образования[3] и основном содержании предмета химии [4] отмечено, что учащиеся должны «использовать приобретенные знания и умения в практической деятельности и повседневной жизни», в том числе для критической оценки информации о веществах, используемых в быту. Поэтому 
содержание обучающих задач при компетентностном подходе отличается от традиционных заданий своей практической направленностью.

Методологическая функция линии практико-ориентированных задач состоит в изучении понятий и методов, объединяющих содержание не только методических, но и предметных линий всего школьного курса химии.

О.Д. Кендиван сформулировал определение понятия «практико-ориентированная химическая задача», отражающее особенности ее содержания: «Практико-ориентированной является задача, направленная на развитие ключевых компетентностей учащегося и выявление химической сущности объектов природы, производства и быта, с которыми человек взаимодействует в процессе практической деятельности». [5]

Решение практико-ориентированных задач происходит по схеме: понимание - применение - анализ - синтез - оценка.

Практико-ориентированные задания можно разделить на три группы:

- теоретические;

- экспериментально-теоретические;

- расчетные;

Теоретические задачи: основа рассмотрения количественных характеристик. Их решение дает возможность учителю развить логическое мышление учащихся, формировать химические понятия, связывать обучение с жизнью. [6,7]

Экспериментально-теоретические задачи: при их выполнении опытным путем на основе имеющихся теоретических знаний разрешаются практические вопросы. Они могут использоваться как средство контроля.

При их выполнении происходит синтез логических, количественных и экспериментальных операций, приобретается умение решать комплексные задачи. [8]

Расчетные задачи: Решая расчетные задачи учащиеся уясняют количественные закономерности, приобретают навык применения математических приемов в изучении химии.

Можно выделить следующие принципы конструирования практико-ориентированных задач по химии в общеобразовательной школе $[9,10]$ :

1. Контекстная задача - эффективный мотиватор учебно-познавательной деятельности учащихся:

- реализует принцип субъектности участников образовательного процесса;

- побуждает учащихся к самостоятельной поста- новке целей и задач учебно-познавательной деятельности;

- учит проводить самоанализ качества и процесса деятельности и ее продукта.

\section{2. Ситуационные задачи:}

- носят поисково-исследовательский характер;

- представляют собой описание ситуации, наиболее типичной для обыденно-практической жизни или имеющей профильную направленность;

- в содержание задания включается изложение условий и постановка проблемы

- выполнение предусматривает актуализацию имеющихся знаний и поиск недостающей информации.

Структура ситуационной задачи такова: она имеет интересное название, описание двух-трех ситуаций, которые выступают мотивационной формой для деятельности учащихся и заданий, которые учащиеся должны выполнить. Для ситуационной задачи необходимо брать темы, которые привлекают внимание школьников. Ситуационная задача должна быть актуальной. Задача должна быть настоящим живым примером, который вызовет неподдельный интерес учащихся.

Хорошо составленная ситуационная задача вызывает чувство сопереживания с главными действующими лицами. Важно, чтобы в задаче была представлена реальная ситуация, которая стимулирует проявление разнообразных эмоций (сочувствие, удивление, радость, гнев и т.д.).

В текст ситуационной задачи необходимо включать цитаты из различных источников, чтобы создать полноценную, реалистичную картину.

Создавая ситуационные задачи, необходимо учитывать возрастные особенности учащихся. Проблема, которая лежит в основе ситуационной задачи, должна быть понятна ученику. Наиболее эффективно использовать систему взаимосвязанных ситуационных задач.

3. Компетентностно-ориентированные задания (тесты) - это тесты, представляющие собой систему калиброванных заданий специфической формы, отличающиеся практико-ориентированной направленностью содержания или проблемным характером.

тесты, представляющие собой систему калиброванных заданий специфической формы, способствующие выявлению как знаниевого, так и деятельностного компонентов компетенций

Специфика компетентностно-ориентированного теста:

- для выполнения необходимы интегрированные знания и умения; 
- практико-ориентированность направленность содержания заданий;

- увеличено число заданий повышенной трудности;

- большой процент заданий открытой формы.

Для иллюстрации приведенной классификации практико-ориентированных заданий приведем пример всех трех видов задач.

\section{Трацишионное замание}

Какие объемы 37-го раствора хлороводородной кислоты плотностью 1,19г/см3 и воды потребуется для приготовления 1 л 10-го раствора плотностью 1,049 г/см3 ? [11]

\section{Контекстные задания}

1. При пониженной кислотности желудочного сока больным назначают разбавленную соляную кислоту, в которой массовая доля хлороводорода равна 8,2 \% ( $\rho=1,04$ г/мл). В аптеке ее готовят из

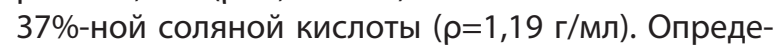
лите объем разбавленной кислоты, которую можно приготовить из 20 мл 37\%-ной кислоты. [12]

2. Наша соседка, Галина Семеновна, работает в аптеке провизором. Вечером, заглянув к нам в гости, она рассказала, какой забавный случай у них сегодня произошел. К ним пришел покупатель, у которого врачи обнаружили пониженную кислотность желудка и рекомендовали ему запивать принимаемую пищу 3\%-м раствором соляной кислоты. В день больной должен выпивать 10 г такого раствора. И, чтобы не ходить часто в аптеку, покупатель попросил продать ему средство сразу на весь год. Но Галина Семеновна отговорила его от такой покупки.

3. Почему фармацевт не рекомендовала делать такую покупку? Какую массу раствора пришлось бы отнести домой покупателю за один раз? Какую массу 100 \%-ной кислоты надо выпить больному за год? [13]

4. В архиве пожарной части города Бенд (США) хранится запись о пожаре, который произошел на строительной площадке. В этот зимний день на стройку завезли негашеную известь и ссыпали её в специально приготовленные у стен дома ямы, которые сверху ничем не прикрыли. Вечером начался сильный снегопад. Эксперты установили, что именно он и был причиной пожара.

Объясните, возможно ли это, и для чего на стройку завезли гашеную известь? [14]

\section{Ситуашионные задания}

1. Кухонные полотенца часто бывают испачканы сажей, особенно если пищу готовят на плите, кото- рая топится дровами. Как можно вывести пятна сажи? Помогут ли современные стиральные порошки, содержащие отбеливатели? Продемонстрируйте выбранный Вами способ, докажите его эффективность. [15]

2. Конструкторы первых космических кораблей и подводных лодок столкнулись с проблемой: как поддерживать на судне или космической станции постоянный состав воздуха, то есть как избавиться от избытка СО2 и восстановить запас кислорода? Предложите возможные способы решения данной проблемы. Выясните, как очищается воздух на современных космических кораблях? На каких химических свойствах основан данный процесс. [16]

3. Одна из глобальных экологических проблем кислотные дожди, которые в 60-70-е годы XX столетия привели нашу планету к катастрофическому экологическому состоянию, уничтожив миллионы гектаров леса в Западной Европе и Скандинавии, загубив все живое в некоторых озерах Норвегии, вызвав всплеск заболеваний и смертности населения. Однако антропогенное загрязнение окружающей среды продолжается. Представьте, что Вас пригласили выступить с докладом на международном конгрессе по охране природы, который может изменить ситуацию. Для подготовки сообщения Вам необходимо обратить внимание на следующие вопросы:

- Каковы причины возникновения кислотных дожей?

- Какие кислоты могут содержаться в капле дождя?

- Когда и где впервые были зарегистрированы первые случаи кислотных дожей?

- Где на Земле зафиксировано самое сильное закисление природных водоемов?

- Охарактеризуйте ущерб, наносимый кислотными дождями природе.

- Какие Вы видите пути решения данной проблемы? [17]

\section{Компетентностно-ориентированные задания (тесты)}

Задание 1 закрытой формы компетентностно-ориентированного теста.

Массовая доля крахмала в картофеле составляет 20\%. Масса глюкозы, которая может быть получена из картофеля массой 405 кг при выходе продукта 70\% составляет
a) $58 \mathrm{kr}$
б) $63 \mathrm{kr}$
в) $125 \mathrm{Kr}$
г) $106 \mathrm{Kr}$ 
Задание 2 открытой формы на дополнение компетентностно-ориентированного теста (предусматривает написание краткого ответа).

За сутки в желудке человека выделяется более 800 мл желудочного сока ( $\rho=1,065$ г/см3). Массовая доля кислоты в желудочном соке составляет 0,4-0,5\%. Масса хлорида натрия, необходимая для образования суточной нормы хлороводородной кислоты, содержащейся в желудочном соке, равна ...

Задание 3 открытой формы со свободно конструируемым ответом компетентностно-ориентированного теста (предполагает написание развернутого ответа на поставленный вопрос).

Ароматический углеводород состава С7H8 повергли бромированию на свету без катализатора. Образовавшееся дибромпроизводное гидролизовали разбавленным раствором гидроксида натрия. Полученный продукт окислили кислородом воздуха при нагревании. Получили вещество состава $\mathrm{C7H6O2,} \mathrm{которое} \mathrm{широко}$ распространено в природе. Это соединение используется в пищевой промышленности в качестве добавки Е210. Его добавляют в джемы, фруктовые добавки, маринады, йогурты. С какой целью? Определите формулу Е210, рассмотрите уравнения всех упомянутых в тексте реакций и назовите вещества. Что Вы знаете о пищевых добавках?
Задание 4 со свободно конструируемым ответом компетентностно-ориентированного теста (предполагает написание развернутого ответа на поставленный вопрос).

Известно, что водолазы, выполняя работы на большой глубине, дышат не сжатым воздухом и не чистым кислородом, а кислородно-гелиевой смесью. Почему?

Нами в ходе анализа методической и педагогической литературы было установлено, что нет четких рекомендации и требований, предъявляемых к включению практико-ориентированных задач в систему школьного химического образования. По этому перед нами возник ряд вопросов: на каких уроках или во внеурочное время стоит рекомендовать использование данного типа задач? Как подбирать задачи?

Исходя из поставленных противоречий нами была разработана методическая система по использованию практико-ориентированных задач по химии в учебное и внеучебное время. Данная система представлена на рисунке 1.

Представленная методическая система основана на следующих принципах:

— логико-научная и профессиональная обусловленность содержания;

- информационная емкость и прогностическая

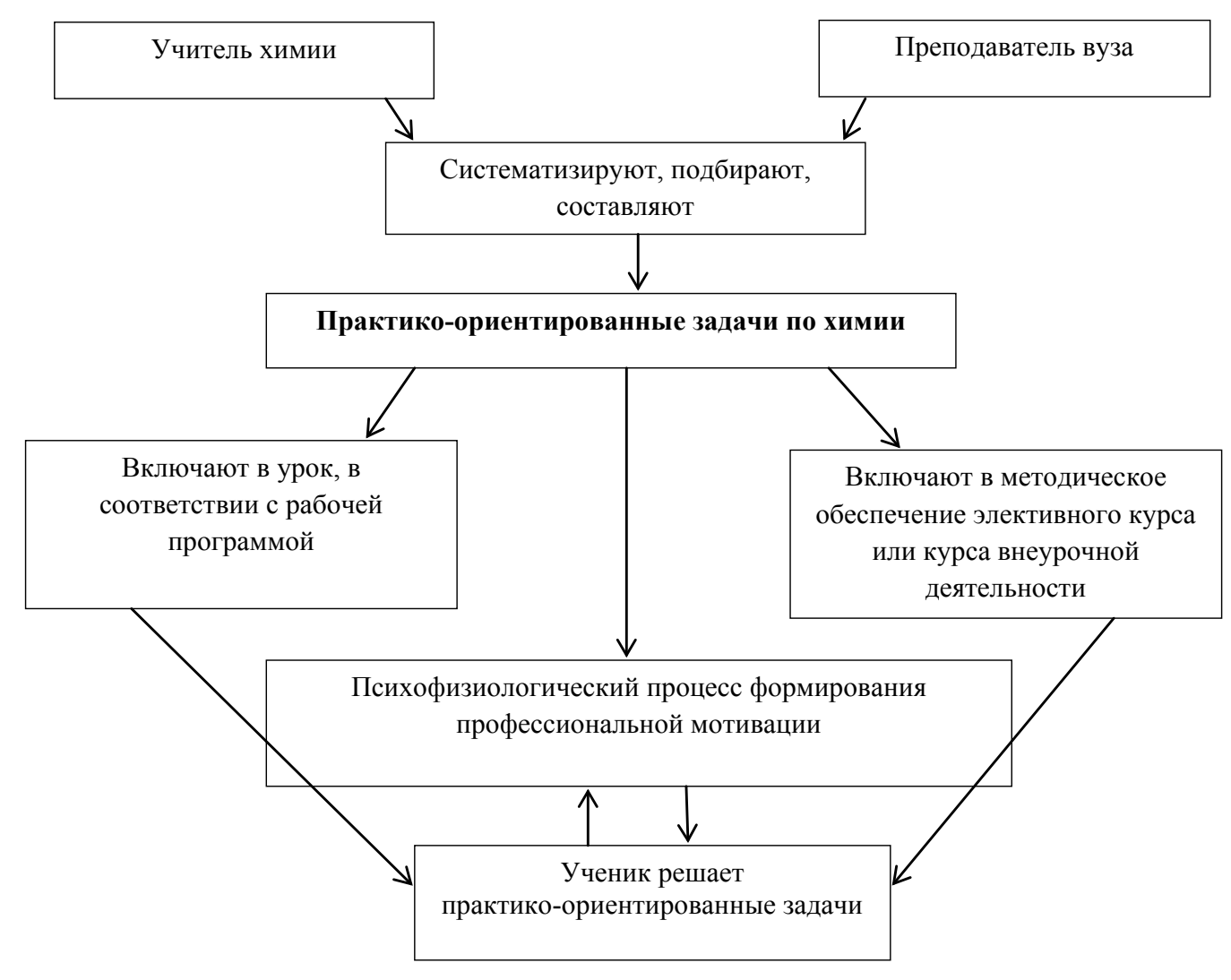

Рис. 1. Методическая система по использованию практико-ориентированных задач по химии в учебное и внеучебное время. 


$$
\begin{aligned}
& \text { ценность; } \\
& \text { - конструктивно - практическая ценность; } \\
& \text { - системность; } \\
& \text { - интеграция. }
\end{aligned}
$$

Для достижения логико-научной обусловленности содержания в основу разработанной системы положены основополагающие научные теории интегрированных дисциплин, необходимые для системного рационального познания, которые рассматриваются в профессиональных программах: строение органических веществ, характеристика основных классов органических веществ и генетические переходы между классами органических веществ.

Принцип информационной емкости означает, что материал используемый в ходе реализации данной системы несет глубокую информацию о природе и обществе, технологических процессах происходящих в промышленности, поскольку при изучении любого объекта, процесса или явления в первую очередь выявляются и анализируются наиболее характерные информационные аспекты.

Прогностическая ценность модели заключается в том, чтобы, осмыслив материал, на основе фактов выдвигать гипотезы решения проблем, делать необходимые обобщения, сопоставления с аналогичными или альтернативными вариантами решения, устанавливать статистические закономерности, делать аргументированные выводы и применять их для выявления и решения новых проблем.

Системность в содержании разработанной методической модели выражается в том, что центром учебного процесса являются представления о единой научной картине мира.

Интеграция содержания - основополагающий принцип построения методических моделей, базисом интеграции является химия, на ее основе формируется содержание интегрированных подходов, она определяет интегративную цель исследования расширение теоретических представлений о роли и месте химии в комплексе наук, изучаемых в средней и профессиональной школе, вузе повышение уровня профессионального мышления специалистов и формирования устойчивой мотивации к обучению, воспитание общественно - активной творческой личности с ноосферным мышлением, способной видеть актуальные задачи и решать их.

Решение проблемы - формирование профориентационной мотивации достигается разработкой методических рекомендации по проведению занятий и уроков на основе практико-ориентированных задач по химии, в которых целевые установки реализуются путем:

- формирования мотивации и системы понятий у учащихся на базе фундаментальных законов и в ходе изучения основного предмета химии;

- формирования основ ноосферного мышления на базе решения проблемных вопросов и практикоориентированных задач по химии;

- анализа и разработки принципов малоотходных и ресурсосберегающих технологий для производств, основанных на органическом синтезе и проработке топлива.

Результатом обучения будет сформированность профориентационной мотивации, целостное экологоцентрического мышление, умение самостоятельно обращаться с информацией, опыт экспериментальной и научно-исследовательской работы.

Особенности применения
практико-ориентированных задач на уроках
химии в рамках реализашии
методической системы

Урок - основная форма организации обучения в современной школе. Различают несколько основных типов урока: урок усвоения новых знаний, урок комплексного применения знаний и умений (закрепления), урок актуализации знаний и умений (повторения), урок систематизации и обобщения знаний и умений, урок контроля знаний и умений, урок коррекции знаний, умений и навыков, комбинированный. Особую роль в организации процесса обучения, в том числе и обучения вопросам планиметрии отводят урокам ознакомления с новым материалом, это обусловлено целевыми установками уроков такого типа. $[50,51]$

Урок ознакомления учащихся с новым материалом или сообщения (изучения) новых знаний - это урок, содержанием которого является новый, неизвестный учащимся материал. На таких уроках в зависимости от их содержания, конкретной дидактической цели и подготовленности учащихся к самостоятельной работе в одних случаях учитель сам излагает новый материал, в других - проводится самостоятельная работа учащихся под руководством учителя, в-третьих - практикуется и то, и другое. Структура урока ознакомления с новым материалом определяется его основной дидактической целью: введением понятия, установлением свойств изучаемых объектов, построением правил, алгоритмов и т.д. Его основными этапами являются:

1. сообщение темы, целей, задач урока и мотивации учебной деятельности;

2. подготовка к изучению нового материала через повторение и актуализацию опорных знаний;

3. ознакомление с новым материалом;

4. первичное осмысление и закрепление связей и от- 
ношений в объектах изучения;

5. постановка задания на дом;

6. подведение итогов урока. $[18,19]$

В силу своего содержания, практико-ориентированные задачи на уроке рассматриваемого типа могут служить средством для создания условий, обеспечивающих формирование у учащихся мотивации к изучению нового материала. Поскольку учащиеся могут в ходе решения данных задач применить знания и навыки из повседневной жизни, а также проверить свой результат на практике.

На таких уроках целесообразно предлагать учащимся для решения практико-ориентированные задачи, для решения которых им необходимо получить новые знания, овладеть новыми умениями. Решение самой задачи происходит непосредственно после изучения нового материала, который будет служить инструментом для ее решения.

Практико-ориентированные задачи являются универсальным дидактическим средством, которое может использоваться на любом из этапов урока. На наш взгляд, применение подобранных нами задач по химии, будет способствовать более осознанному восприятию учебного материала учащимися, а так же повышению интереса, что как следствие повлияет на мотивацию в изучении данной темы.

Педагогический эксперимент по реализации раз- работанной методической системы по использованию практико-ориентированных задач по химии в учебное и внеучебное время был проведен на базе МБОУ школа №129 г.о. Самара. Особенность одного из направлений работы данного образовательного учреждения заключается в том, что в 10-11 классе осуществляется профильное обучение по химии, с четко выделенным направлением профессиональной ориентации - Роснефть. Организация ООО «Роснефть» является спонсором в развитии данного образовательного направления и наставником для учащихся. На базе данной организации для учеников проводятся профориентационные мероприятия и знакомство с будущими профессиями. Так же у данной школы существует договор о сотрудничестве с ФГБОУ ВО «Самарский государственный технический университет». Преподаватели вуза проводят дополнительные занятия с учащимися старших классов, работают в качестве учителей при проведении занятий по элективным курсам и т.д.

Исходя из описанной системы работы в базовом образовательном учреждении, в основу разработки образовательного поля практико-ориентированных задач был положен раздел органической химии, который изучается в 10 классе.

На рисунке 2 показано образовательное поле междисциплинарных проблем, которые следует рассматривать в содержании практико-ориентированных задач по химии, направленных на формирование профориентационной мотивации.

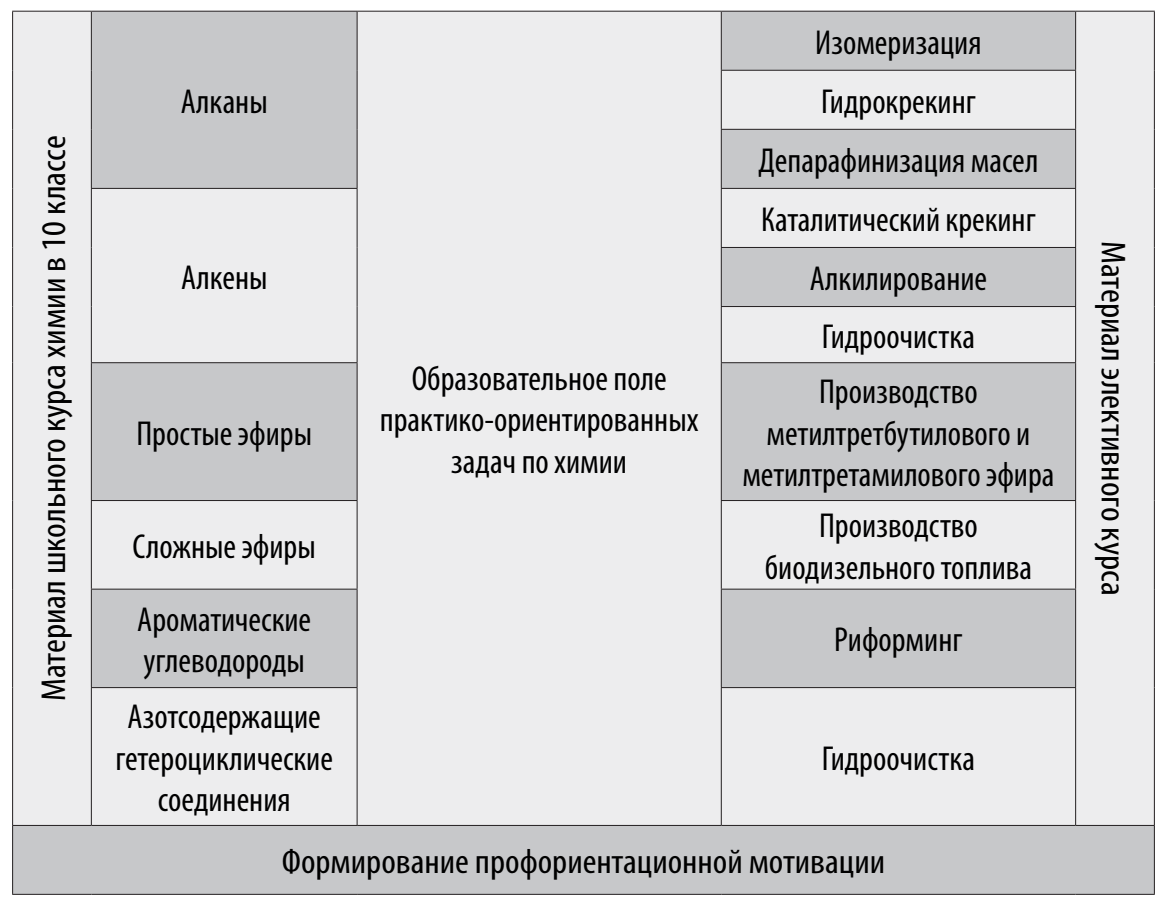

Рис. 2. Образовательное поле практико-ориентированных задач по химии, направленных на формирование профориентационной мотивации. 
Таблица 1.

Соотнесение формируемых понятий школьного курса химии с практико-ориентированными задачами по химии

\begin{tabular}{|c|c|c|c|c|}
\hline $\begin{array}{l}\text { Раздел школьного } \\
\text { учебника }\end{array}$ & Тема в школьном учебнике & Формируемые понятия & $\begin{array}{c}\text { Типы практико-ориентиро- } \\
\text { ванных задач }\end{array}$ & $\begin{array}{c}\text { Кол-во задач подобранных } \\
\text { по данной теме }\end{array}$ \\
\hline \multirow{3}{*}{ Углеводороды } & Алканы & $\begin{array}{c}\text { Изомеризация, Гидрокрекинг, } \\
\text { Депарафинизация масел }\end{array}$ & Контекстные задачи & 10 \\
\hline & Алкены & $\begin{array}{c}\text { Каталитический крекинг, Алкилиро- } \\
\text { вание, Гидроочистка }\end{array}$ & Контекстные задачи & 10 \\
\hline & $\begin{array}{c}\text { Ароматические углево- } \\
\text { дороды }\end{array}$ & Риформинг & Контекстные задачи & 7 \\
\hline \multirow{2}{*}{$\begin{array}{l}\text { Кислородосодержа- } \\
\text { щие соединения }\end{array}$} & Простые эфиры & $\begin{array}{c}\text { Производство метилтретбутилово- } \\
\text { го и метилтретамилового эфира }\end{array}$ & Контекстные задачи & 7 \\
\hline & Сложные эфиры & $\begin{array}{c}\text { Производство биодизельного } \\
\text { топлива }\end{array}$ & Контекстные задачи & 7 \\
\hline $\begin{array}{c}\text { Азотосодержащие } \\
\text { соединения }\end{array}$ & $\begin{array}{l}\text { Азотсодержащие гетеро- } \\
\text { циклические соединения }\end{array}$ & Гидроочистка & Контекстные задачи & 7 \\
\hline
\end{tabular}

Таблица 2.

Результаты анкетирования учащихся 10 А класса МБОУ школа № 129 г.о. Самара в 2018-2019 учебном году на контрольном этапе педагогического эксперимента.

Вопрос № 13 анкеты по профессиональному самоопределению (автор С.С. Гриншпун): «Хотели бы вы изменить профиль трудового обучения? »

Кол-во учеников принявших участие в анкетировании

24

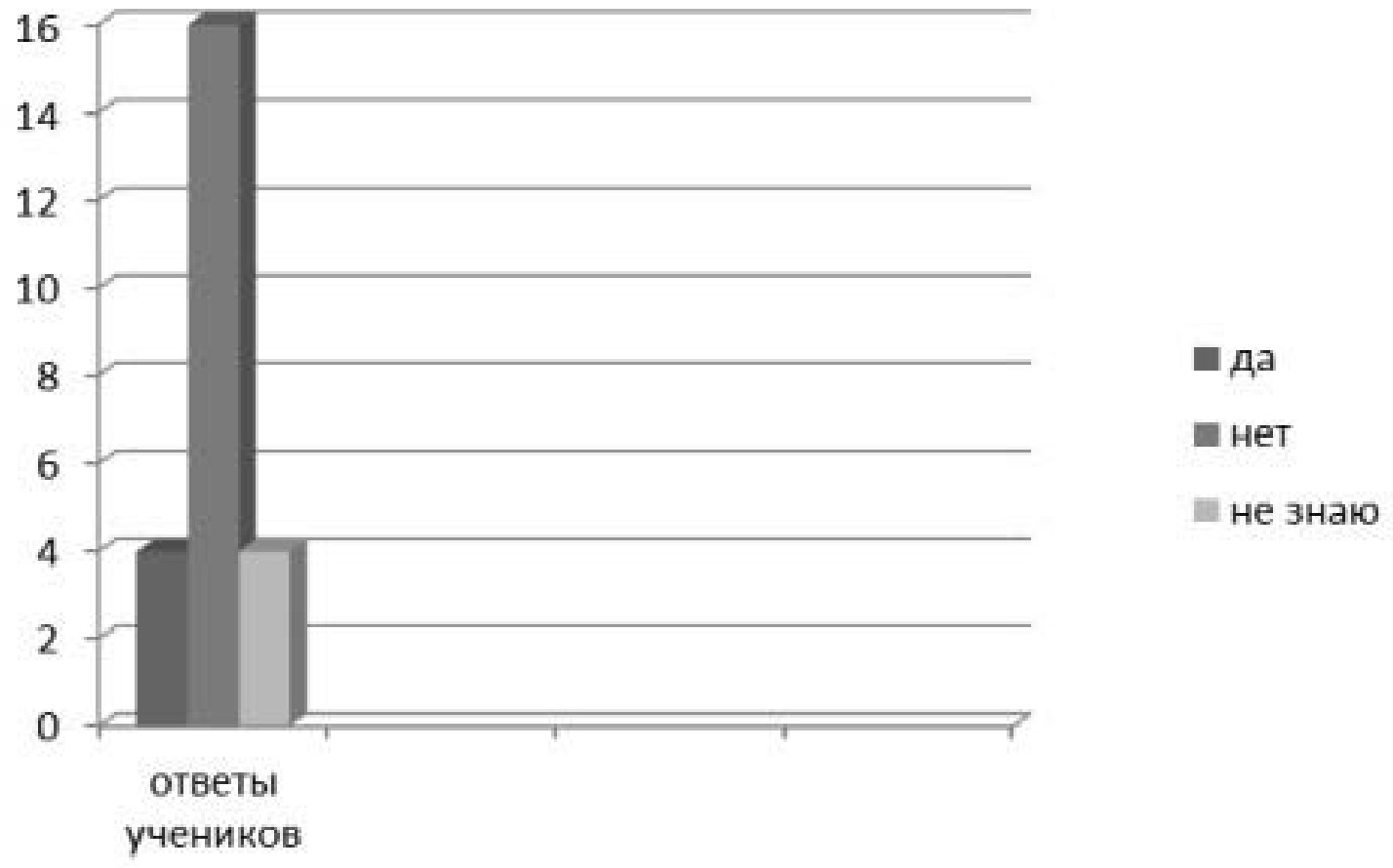

Рис. 3. Диаграмма результатов анкетирования учащихся 10 классов в 2018 - 2019 году по вопросу анкеты №13 по профессиональному самоопределению (автор С.С. Гриншпун). 
Рекомендации учителю химии по внедрению в учебный процесс практико-ориентированных задач мы представили в таблице 1, в которой приведены темы и описаны практико-ориентированные задачи по химии к данным темам, за основу был взят учебник и программа О.С. Габриеляна для 10 класса профильного обучения.

Практико-ориентированные задачи по химии могут использоваться непосредственно на уроках или в форме домашнего задания для учащихся 10 классов. Так же необходимо отметить, что данные задачи могут быть использованы в рамках проведения занятий по элективному курсу «Органическая химия как элемент нефтехимического производства». Данный курс проводиться на базе МБОУ школа №129 г.о. Самара уже на протяжении трех лет совместно с преподавателями ФГБОУ ВО «Самарский государственный технический университет». В частности, последнее время занятия по данному элективному курсу проводит Солманов П.С., К.Х.Н., ассистент ФГБОУ ВО «СамГТУ».

Для выявления профориентационной мотивации была на контрольном этапе использована анкета по профессиональному самоопределению (автор д.п.н. С.С.
Гриншпун [20].

В качестве примера приведем ответы на один из вопросов анкетирования учащихся 10 классов (табл.2).

Данные представленные в таблице для большей наглядности представлены также на рисунке 3.

Исходя из полученных данных можно сделать вывод о том, что 66,7\% учащихся не собираются менять профиль обучения и переориентироваться на другие виды профессий. Этот показатель достаточно высокий и может считаться как показатель эффективной работы всей системы профориентационной направленности в данном образовательном учреждении.

В заключении необходимо отметить, что в статье рассмотрена методическая система по использованию практико-ориентированных задач по химии в учебное и внеучебное время; определено образовательное поле междисциплинарных проблем, которые следует рассматривать в содержании практико-ориентированных задач по химии, направленных на формирование профориентационной мотивации и подобраны и систематизированы практико-ориентированные задачи по химии.

\section{ЛИТЕРАТУРА}

1. Федеральный государственный стандарт основного общего образования [Электронный ресурc]. URL: http://xn--80abucjiibhv9a.xn--p1ai/\%D0\%B4\%D0\%B E\%D0\%BA\%D1\%83\%D0\%BC\%D0\%B5\%D0\%BD\%D1\%82\%D1\%8B/543/(дата обращения: 25.09.19).

2. Федеральный государственный образовательный стандарт среднего общего образования [Электронный ресуpc]. URL: http://xn--80abucjiibhv9a.xn--p1ai/ \%D0\%B4\%D0\%BE\%D0\%BA\%D1\%83\%D0\%BC\%D0 (дата обращения: 25.09.19).

3. Фундаментальное ядро содержания общего образования [Электронный ресурс]. URL: http://www.dagminobr.ru/storage/files/2015/f (дата 0бращения: 25.09.19).

4. Основное содержание предмета «Химия» на ступени основного общего образования [Электронный ресурc]. URL: http://teacher-chem.ru/osnovnoesoderzhanie-himiya-000.html (дата обращения: 25.09.19).

5. Березин А.Н. Сборник творческих и познавательных задач по химии. [Текст] - М.: Дрофа, 1985.

6. Брушлинский А. В. Мышление и прогнозирование. [Текст] - М., 1979. — 230 .

7. Протасов П.Н., Цитович И.К. Методика решения расчетных задач по химии. Пособие для учителя. [Текст] - М.: Просвещение, 1978.- 126с.

8. Гергей Т., Машбиц Е.И. Место задачи в деятельности. [Текст] — В сб.: Теория задач и способов их решения.— Киев, 1973. С. 3-13.

9. Дмитров Е.Н. Познавательные задачи по органической химии и их решения. [Текст] - Тула: «Арктоус», 1996.

10. Костюк Г. С., Балл Г. А. Категория задачи и ее значение для психолого-педагогических исследований. [Текст] //Вопросы психологии. 1977. № 3. С. 12-23.

11. Кузнецова Н.Е., Лёвкин А.Н. Задачник по химии для учащихся 8 класса общеобразовательных учреждений. [Текст] - М.: Вентана-Граф, $2008 .-128$ с.

12. Кузьменко Н.Е., Еремин В.В. 2400 задач по химии для школьников и поступающих в вузы. [Текст] - М.: Дрофа, 1999.- 560с.

13. Увлекательный мир химических превращений: Оригинальные задачи с решениями [Текст]/ А.С. Суворов и др. - Химия, 1998.

14. Малышев А.И. Оригинальные задачи по химии 8-11 класс. [Текст] - М.: Гуманитарный издательский центр ВЛАДОС, 2006. - 151с.

15. Химия 8 класс. Карточки заданий к учебнику Габриеляна 0.С. [Текст] - Саратов: Лицей, 2004. - 112 с.

16. Хомченко И.Г. Решение задач по химии. [Текст] - М.: Новая Волна, 2006.- 256с.

17. Ярославцева Т.С. Решение расчётных задач по химии в средних ПТУ. [Текст] - М.: Высш. шк., 1985.

18. Методика преподавания химии [Текст]/ под ред. Н.Е. Кузнецовой. М.: Просвещение, 1984.

19. Методика преподавания химии в средней школе: Общая методика. Учеб. Пособие для студентов пед. ин-тов [Текст]/ В.А. Оганесян, Ю.М. Колягин, Г.Л. Луканкин, В.Я. Саннинский. - 2-е изд., перераб. и доп. М.: Просвещение, 1980.

20. Климов, Г.А. Психология профессионального самоопределения. [Текст]/ Г.А. Климов. - Ростов-на-Дону: «Феникс», 1996. 512 с.

( ) Нелюбина Елена Георгиевна (nelubina.elena@pgsga.ru), Панфилова Людмила Владимировна (panfilova@pgsga.ru). 